\title{
The way the mistery of the Mattei's case was solved
}

\author{
Donato Firrao, Graziano Ubertalli, Paolo Matteis, Chiara Pozzi \\ Politecnico di Torino, Dipartimento di Scienza dei Materiali e Ingegneria Chimica, C.so Duca degli Abruzzi, 24, 10129 Torino, \\ Italia; donato.firrao@polito.it
}

\begin{abstract}
Enrico Mattei, the President of the Italian oil conglomerate, ENI, was about to land in Milan Linate Airport on October 27, 1962 when his airplane crashed on the ground due to a then unexplained accident. The investigation, reopened more than 30 years later, implied complete re-examining of the theories on macroscopic and lattice deformations under high velocity waves emanating from a small charge explosion.

Various macro- and micro-structural changes are induced by an explosion and by the resulting shear stresses in metals exposed to it. At the microstructural level multiple slip bands or mechanical twins, induced from the pressure wave caused by an explosion, can be observed. The occurrence of either ones depend on the type of metal, the pressure and the strain rate. The temperature wave may also cause surface alterations. Different situations regarding stainless steels, aluminium, copper and gold alloys are analysed.

Calculations to evaluate which deformation mechanism is eligible for different FCC metals and alloys are reported. Results of field explosion experiments are incorporated into the evaluation of microstructural signs possibly induced on metal targets by an unknown explosive event.

Revisited theories were applied to the Mattei forensic case, reaching the conclusion that the aircraft had fallen following an on board small charge explosion.
\end{abstract}

KEYwORDS. Slip deformation; Mechanical twin deformation; Pressure waves; Stacking faults energy; Explosion; Microstructural changes.

\section{INTRODUCTION}

The fact

n October 27, 1962 the airplane which was taking back to Milan Enrico Mattei, the then President of the Italian oil conglomerate, ENI, crashed on the ground minutes from landing at the Milan Linate airport. It ended up on a field in the small village of Bascapè in Pavia county, bordering the Milan county in Lombardy. Wrecks of the aircraft were found dispersed by a line of a tree (Figs. 1, 2), his skin-stripped left hand, high on a branch.

The pilot, Irnerio Bertuzzi, since long time in the ENI President pilots' team, was very experienced with 11260 cumulated flight hours.

The wreckage was collected without precise recording of the exact location of each finding and ended piled up (Fig. 3), and later destroyed by re-melting, after a Pavia Court ruling that the aircraft had fallen by an unexplained accident. A Morane Saulnier 760 B, 4 passengers jet-executive, the airplane had been delivered to ENI in November 1961 (Fig. 4). Mattei was seated on the front right seat (Fig. 5).

\section{The forensic investigation}

A Pavia Court revisiting of the case occurred in 1994, under the impulse of Public Prosecutor Vincenzo Calia, following revelations by a Mafia repentant in a Palermo (Sicily) trial. 
Not too much had been left available for further investigations, mainly personal object preserved by the Mattei Family; the broken gold family ring (Fig. 6), his watch and briefcase, a few documents.

Furthermore, a dashboard instrument (Triple Indicator, Fig. 7) had been gathered in the morning of October 28, 1962 by an ENI employee and kept on his desk within its steel case (Fig. 8), as a souvenir.

A coroner autopsy performed on the corpses of Mattei and Bertuzzi allowed to retrieve inside them metal fragments clearly pertaining to the aircraft, as well as a leg of the third passenger, an American journalist, Mr. Mc Hale, who was seated on the back left seat (Fig. 5).

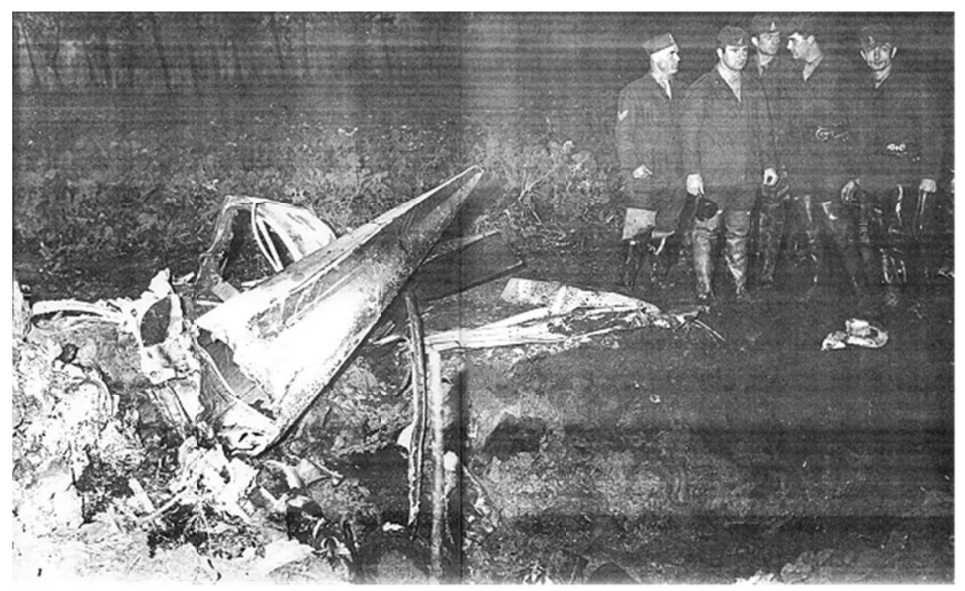

Figure 1: October 27, 1962: Mattei’s aircraft falls in Bascapè (Pavia county), $15 \mathrm{~km}$ from Milan Linate Airport (Black and white photographs from original police ones, taken in the same night).

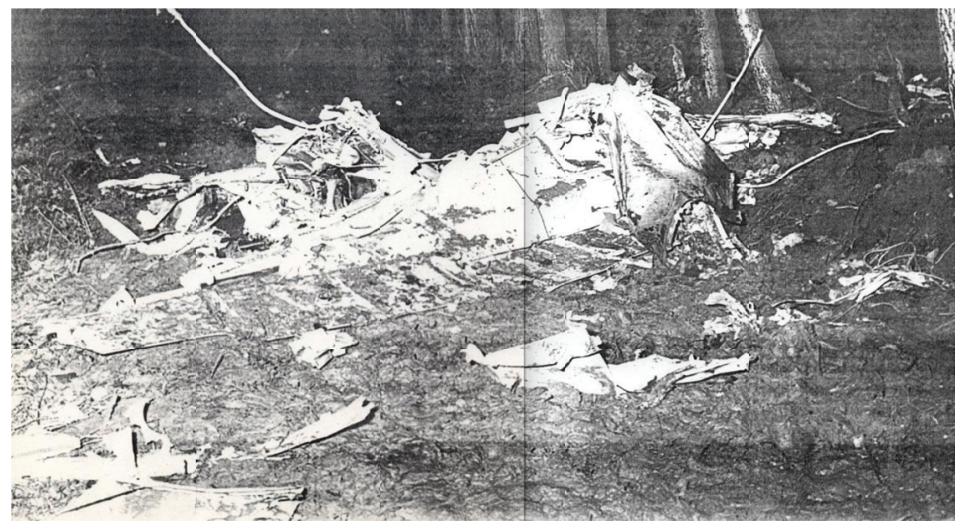

Figure 2: Aircraft wreckage by a line of tree bordering a field in Bascapè (Pavia county).

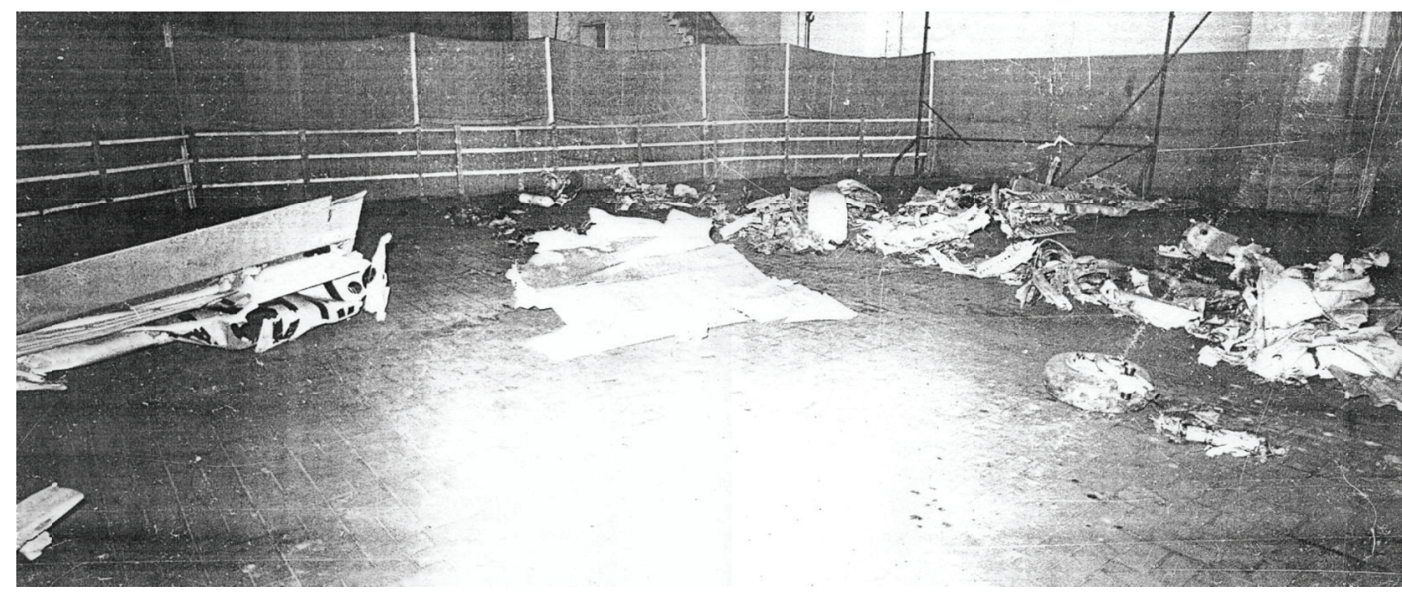

Figure 3: Piled up retrieved wreckage. 


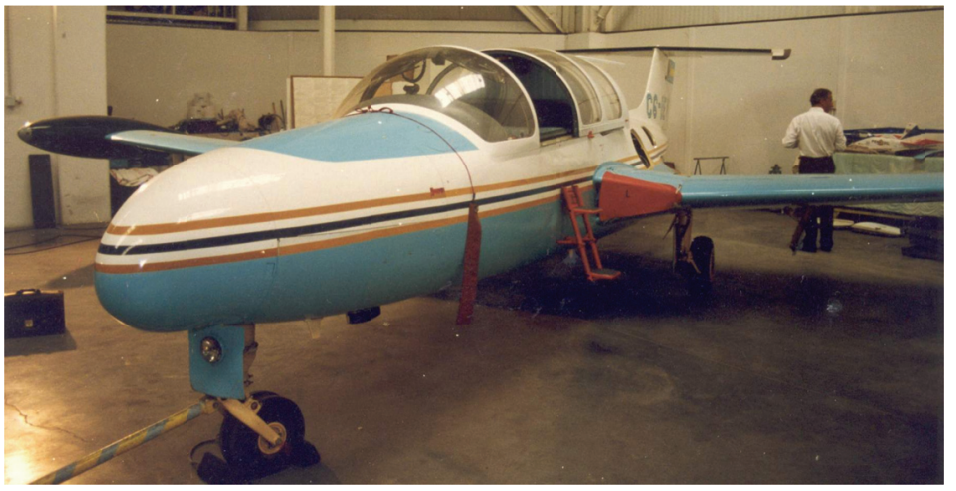

Figure 4: The plane twin to the crashed one. The aircraft was a double-jet executive plane, Morane Saulnier, 760 B model. Both the planes had been commissioned in November 1961.

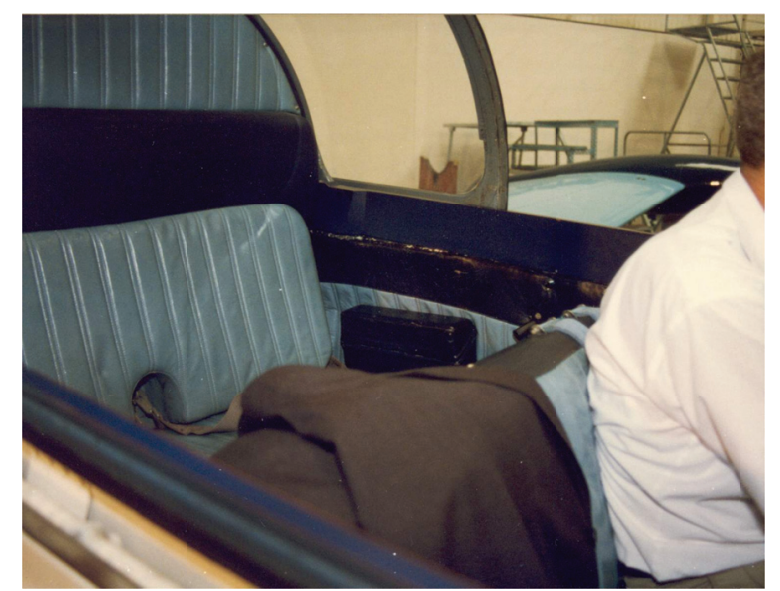

Figure 5: Cockpit of the executive jet plane. Mattei was in the right front seat by the pilot. An American journalist, William Mc Hale, was seated behind the pilot and talking with Mr. Mattei.

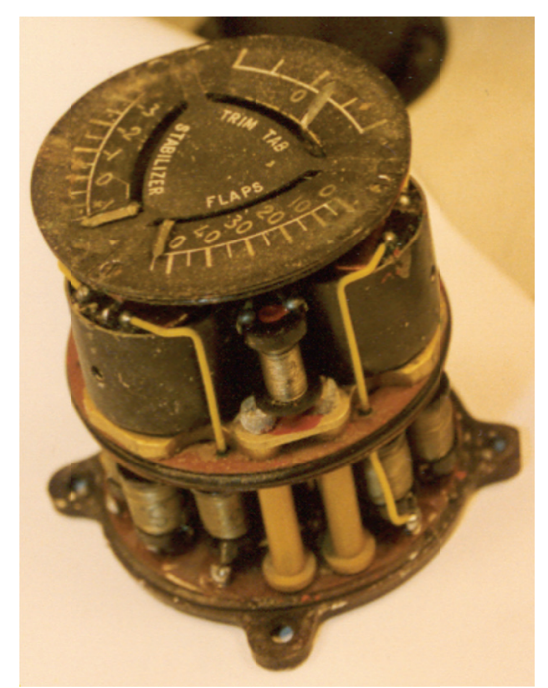

Figure 7: A triple indicator from the fallen aircraft dashboard.

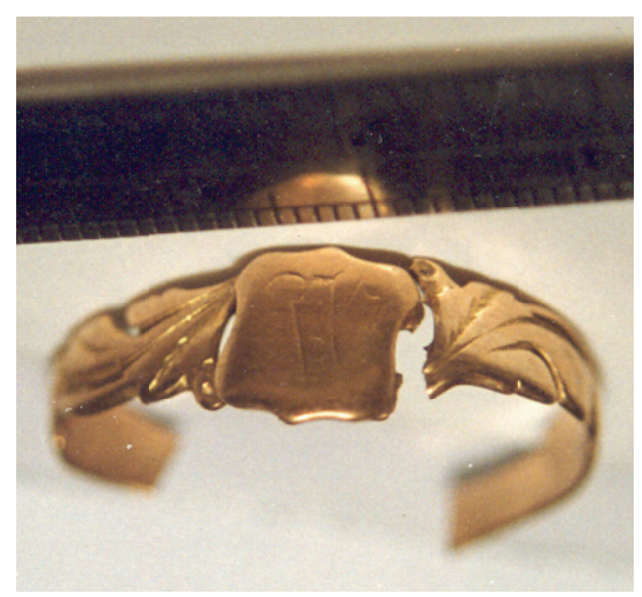

Figure 6: The broken ring of Mr. Mattei retrieved among the family memorabilia.

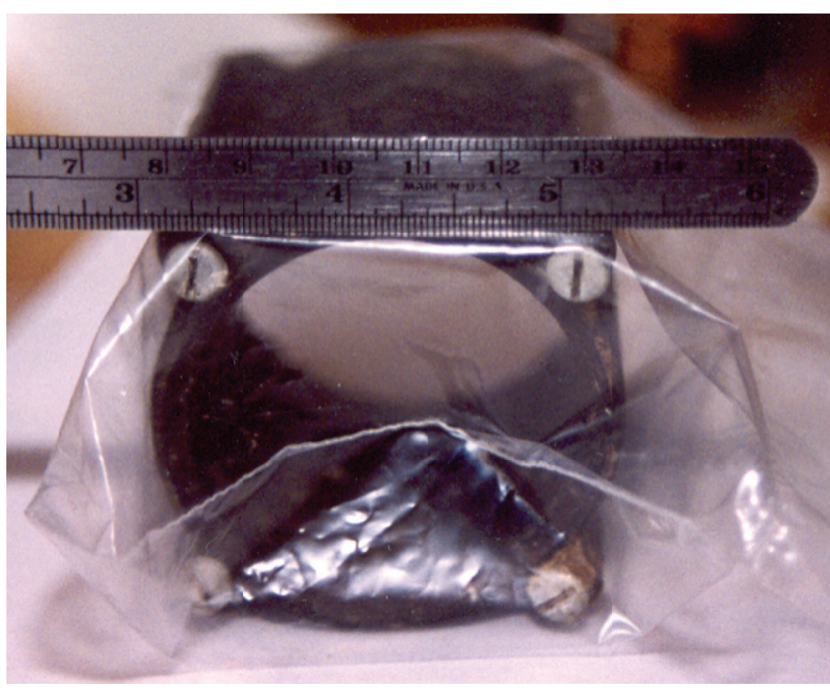

Figure 8: The triple indicator case with stainless steel screws.

An explosion on board having been always suspected, metal sections of retrieved objects were carefully prepared and examined by optical and electronic microscopy to ascertain the presence of lattice deformation signs due to the pressure and heat wave. In fact, usual signs of explosions, i.e. evident macro deformations induced by explosion, partial melting at 
grain boundaries, gas washing on surface or rolled edges developing at external surface of fracture zones were not present in the objects retrieved fairly intact or on surfaces of the fragments retrieved in the bodies, which had been corroded by body liquids during the more than thirty years elapsed since the corpse burials.

The metallographic investigation then focused on the gold ring and the stainless steel screws of the triple indicator case, alongside the aluminium alloy fragments retrieved from the bodies.

The screws and the ring could be positioned fairly well on the aircraft scene at the moment of the accident: the instrument was on the upper left corner of the dashboard (Fig. 9), the left Mattei hand with the ring was probably staying just in front of the centre of the dashboard.

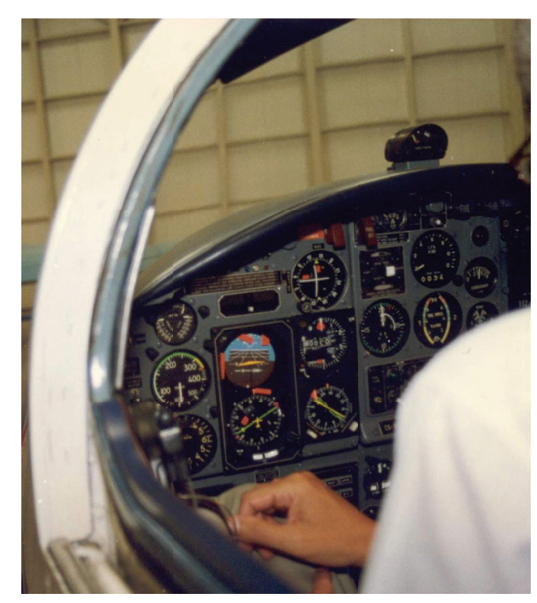

Figure 9: The triple indicator was positioned on the upper left corner of the airplane dashboard.

\section{REVIEW OF PREVIOUS WORK}

\section{Microstructural effects of an explosion on FCC metals}

he review has been limited to FCC metals, given the type of alloys on which the forensic investigation had to be focused.

L Inside a metal component the primary overpressure wave yields a compression wave, which, upon reaching a free surface, is reflected as a tension wave. Both the compression wave and the reflected wave may cause the overcoming of the critical shear stress for slip or mechanical twinning. In the case of objects quite close to the explosive charge, or if the charge is high, the maximum stress is reached; then the material breaks up, usually by delamination [1].

In the case of small charges the overpressure does not cause breakage, but can cause compressive plastic deformation in objects placed quite close to the charge. As the target-to-charge distance increases, only lattice deformation may occur. Moreover, if the distance is fairly high in respect to the scale of the phenomenon, lattice deformation is restricted to favourably oriented crystals and can propagate to the nearest ones. In the extreme case, only a few plastic deformations can appear in isolated favourable oriented grains at or close to the compression wave impinged surface.

Microstructural signs detectable by microscopy inside the crystals can be either mechanical twins or heavy multiple slip bands. Depending on the charge mass and the target-to-charge distance, crystal habit and stacking fault energy of the specific alloy dictate which of the above two morphologies prevails. X-ray diffraction analysis may be useful to detect lattice modifications.

Inhomogeneous distributions of twins inside the component having be detected in respect of the incident overpressure wave [2], microscopic examinations have to be as thorough as possible.

Temperature effects may also affect the microstructure. It is known that in high strength steels or Al alloys a peculiar tendency to localised plastic deformation in thin bands (shear bands) is present, with a very localised temperature raise and hence equally localised microstructural variations. Aside from this, all crystal deformations induce a local internal energy increase. The corresponding material being less stable, recrystallization phenomena under the temperature wave following the compression wave are facilitated owing to the reduced recrystallization temperature.

Various recrystallization stages can be envisioned depending on the intensity of both overpressure and overtemperature waves as well as on the actual material recrystallization temperature: (i) no recrystallization; (ii) limited recrystallization (at 
grain boundaries) with a dual grained structure; (iii) complete recrystallization with a totally fine structure; (iv) total recrystallization and grain growth.

If complete recrystallization is attained with the overpressure wave being still active, newly formed crystals may undergo twinning or multiple slip. Due to the temperature attenuation inside the material, recrystallization phenomena are more evident in zones closer to the detonation front incidence point.

Due to the lack of well organised information on mechanical twins and multiple slip bands in FCC metals undergone an explosion, it can be useful to further investigate these kinds of deformation mechanisms [3].

\section{Crystal deformation mode: slip versus twinning}

In single crystals the competition between slip and mechanical twinning is ruled by the respective values of the critical resolved shear stresses, the lower being the one that predominates in objects exposed to a detonation front.

The critical resolved shear stress for slip, hereafter indicated as $\tau_{c, \text { slip }}$, has values in the vicinity of $10^{-4} \div 10^{-5} \mathrm{G}$, with $\mathrm{G}$ being the elastic shear modulus; $\tau_{\mathrm{c}, \text { slip }}$ strongly increases upon lowering the temperature or increasing the deformation rate. At room temperatures and quasistatic deformation rates $\left(10^{-5} \div 10^{-1} \mathrm{~s}^{-1}\right)$, maximum values for $\tau_{c, s l i p}$ vary from $8 \mathrm{MPa}$ for steels to $4 \mathrm{MPa}$ for copper alloys and $3 \mathrm{MPa}$ for aluminium alloys, with the minimum ones being one order of magnitude lower.

The critical shear stress $\tau_{c, \text { slip }}$ is highly influenced by composition variations (even small traces of foreign atoms highly increase its value); it is also affected by the temperature (it increases for decreasing temperatures) mostly in BCC metals, less in the FCC and HCP ones. As a matter of fact, in close-packed metals the increase of $\tau$ with $1 / \mathrm{T}$ is limited in pure metals (almost null in $\mathrm{Al}$ ) and more pronounced in alloys, as stainless steels. The deformation rate has a similar influence; when $d \varepsilon / d t$ increases, the slip critical shear stress remarkably increases.

As it regards mechanical twinning, one has to note that the existence of a critical component of shear stress, $\tau_{c}$, was known early from an historical point of view, so that Schmidt's law, which allows to determine the load to be applied with crystals orientation dates back to 1931 [4], even before the existence of dislocation were postulated. On the other hand, debate to decide whether a similar critical component for mechanical twinning deformation existed lasted long; only at the end of the Fifties, beginning of the Sixties, it was possible to suggest some values for critical twinning stress. Those values are listed afterwards: about $150 \mathrm{MPa}$ for copper, 55-90 MPa for $\mathrm{Cu}-8.9 \% \mathrm{Al}$ alloys, $300 \mathrm{MPa}$ for nickel, $50 \mathrm{MPa}$ for silver, $100 \mathrm{MPa}$ for gold, between 50 and $100 \mathrm{MPa}$ in silver-gold alloys [5], with data ranging from 75 and $100 \mathrm{MPa}$ for the alloys at $75 \% \mathrm{Au}[6]$. For the sake of comparison, values from 5 to $35 \mathrm{MPa}$ have been suggested for zinc, from 4 to $13 \mathrm{MPa}$ for tin and from 210 to $300 \mathrm{MPa}$ for pure iron at $15 \mathrm{~K}$.

Thus, the critical resolved shear stress for mechanical twinning, hereafter indicated as $\tau_{c, \text { twin, has }}$ usually much higher values than $\tau_{c, \text { slip. }}$. In fact, in common tension tests, mechanical twins appear only at higher applied stresses than slip bands. $\tau_{c, \text { twin }}$ is mainly influenced by the stacking-fault energy, $\gamma_{\mathrm{sf}}$, and increases as the latter increases.

Contrary to $\tau_{c, s l i p}, \tau_{c, \text { twin }}$ does not vary with the deformation rate and it seems to mildly decrease upon lowering the temperature as does $\gamma_{\mathrm{sf}}$ [7]. In fact, as it regards Cr-Ni stainless steel, there is a decrease of $\gamma_{\mathrm{sf}}$ values between 0.05 and 0.1 $\mathrm{mJ} / \mathrm{m}^{2}$ per every temperature degree in a range between 400 and $200 \mathrm{~K}[8,9,10]$. In particular, for a stainless steel with $16 \% \mathrm{Cr}$ and $13 \% \mathrm{Ni}, \gamma_{\mathrm{sf}}$ changes from 14.5 to $10 \mathrm{~mJ} / \mathrm{m}^{2}$ passing from 300 to $200 \mathrm{~K}$.

Metals and metal alloys having high $\gamma_{\mathrm{sf}}$ values will deform mainly by slip. This behaviour is observed in $\mathrm{Al}$ and $\mathrm{Ni}$, which show the highest $\gamma_{\mathrm{sf}}$ values as reported in Tab. $1^{*}$. On the contrary, additions of alloying elements causing a decrease of $\gamma_{\mathrm{sf}}$ facilitate twinning deformation: a $30 \% \mathrm{Zn}$ brass plastically deforms by twinning easier than $\mathrm{Cu}$, because the addition of $\mathrm{Zn}$ to $\mathrm{Cu}$ lowers $\gamma_{\mathrm{sf}}$ as its percentage increases.

It can be concluded that only at low temperatures and very high deformation rates mechanical twinning is the favoured deformation mechanism in single crystals.

In polycrystals, which usually compose common objects undergoing explosions, the competition between the two deformation mechanisms is governed by the respective Hall-Petch type relationships [11, 12], namely

$$
\sigma_{\mathrm{y}}=\sigma_{\mathrm{fs}}+\mathrm{k}_{\mathrm{s}}\left(\mathrm{d}^{-1 / 2}\right)
$$

the known formula for slip and

$$
\sigma_{\mathrm{y}, \mathrm{tw}}=\sigma_{\mathrm{ftw}}+\mathrm{k}_{\mathrm{tw}}\left(\mathrm{d}^{-1 / 2}\right)
$$

derived for twinning.

\footnotetext{
${ }^{*}$ Values of $\gamma_{\mathrm{sf}}$ may differ from those reported in the Tab. 1 if measurements taken by other authors are taken into account.
} 


\begin{tabular}{lc}
\hline METALS AND ALLOYS & $\gamma_{\mathrm{sf}}$ values $\left(\mathrm{mJ} / \mathrm{m}^{2}\right)$ \\
$\mathrm{Al}$ & 166 \\
$\mathrm{Cu}$ & 80 \\
$\mathrm{Brass}(10 \% \mathrm{Zn})$ & 35 \\
$\mathrm{Brass}(30 \% \mathrm{Zn})$ & 15 \\
$\mathrm{Au}$ & 42 \\
$\mathrm{Ag}$ & 21 \\
$\mathrm{Ni}$ & 128 \\
Austenitic stainless steels AISI 304-316 & 21 \\
Austenitic stainless steels AISI 310 & 40 \\
Austenitic stainless steels Mn-Cr & 11 \\
\hline
\end{tabular}

Table 1: Stacking-fault energy $\left(\gamma_{\mathrm{sf}}\right)$ values of some metals and alloys at room temperature.

The Peierls-Nabarro stress for slip, $\sigma_{\mathrm{fs}}$, depends on the temperature and deformation rate in a manner similar to $\tau_{c, s l i p}$, whereas the analogous stress, $\sigma_{\mathrm{ftw}}$, following the path set for by $\tau_{\mathrm{c}, \mathrm{twin}}$, does not depend on the deformation rate and mildly reduces with the temperature.

Therefore, at high deformation rates, such as those usually encountered in explosions, $\sigma_{\mathrm{y}}$ can go over $\sigma_{\mathrm{y}, \mathrm{tw}}$ if this one is not too high.

Cases referring to $\mathrm{Cu}, \mathrm{Al}, \mathrm{Au}$ and their alloys, as well as stainless steels, are hereby analyzed, since metals of their kind can be usually encountered when exploring the possibility of bomb explosions as the cause of an aircraft crash.

The Eqs. 1 and 2 can be represented by straight lines having $k_{\mathrm{s}}$ and $\mathrm{k}_{\mathrm{tw}}$ as angular coefficient, respectively. As it regards $\mathrm{Cu}$, Meyers et al. [13] suggested that $\mathrm{k}_{\mathrm{tw}}$ is about twice as $\mathrm{k}_{\mathrm{s}}$. The values of $\mathrm{k}_{\mathrm{s}}$ is not much influenced by the deformation rate for low values of applied elongations, but an increase of the deformation rate, from $10^{-3}$ to $10^{6} \mathrm{~s}^{-1}$, makes the HallPetch straight line for slip to move upwards parallel to itself, intersecting the straight line for twinning (Fig. 10). In these conditions fine grain copper (grain dimensions lower than $50 \mu \mathrm{m}$ ) undergoes slip, whereas coarse grain copper deforms by twinning. Analogous considerations are valid also for brasses; here, unlike copper, in the case of explosion, twinning is always favoured at all grains dimensions because brass- $\sigma_{\mathrm{ftw}}$ is quite smaller than $\mathrm{Cu}-\sigma_{\mathrm{ftw}}$.

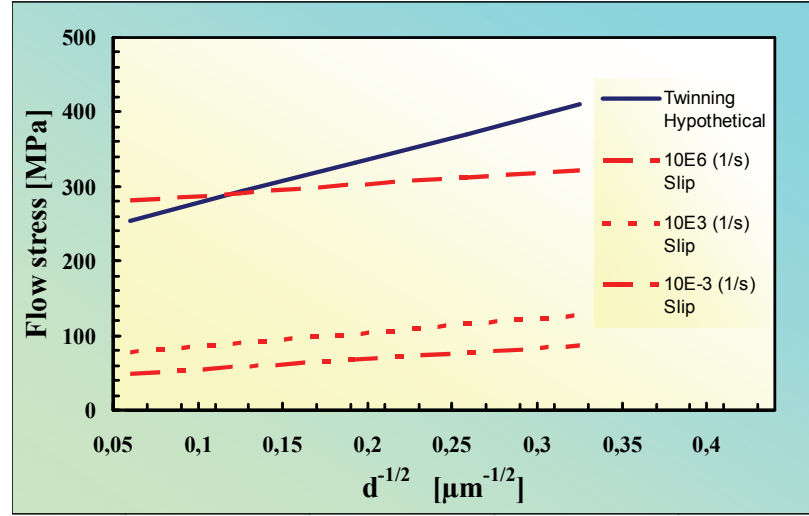

Figure 10: Hall-Petch plots for plastic flow slip $\left(10^{-3}, 10^{3}\right.$ and $\left.10^{6} \mathrm{~s}^{-1}\right)$ and twinning (Hypothetical) for $\mathrm{Cu}$, as suggested by Meyers et al. [13].

Also for stainless steels (AISI 304) $\mathrm{k}_{\mathrm{tw}}$ is about twice as $\mathrm{k}_{\mathrm{s}}$ at 1 and $5 \%$ deformations levels and it increases, while approaching the yield point, especially if grains dimensions exceed $55 \mu \mathrm{m}$. Samples with grains dimensions varying from 23 to $187 \mu \mathrm{m}$ were either cold rolled or shock loaded [14]: in the cold rolled samples slip is the only way of deformation, whereas the shock loaded ones mainly exhibit twinning, accompanied by the formation of platelets of $\varepsilon$ martensite, particularly evident in the smaller grains. For the transformation $\gamma \rightarrow \varepsilon$ a $\sigma_{\varepsilon}$ tension is necessary, whose value lowers as grain dimensions decrease. Thus $\sigma_{\varepsilon}$ can become lower than $\sigma_{\mathrm{ftw}}$ when crystals are below a certain dimension. The coexistence of mechanical twinning and $\varepsilon$ martensite was observed during tension tests on FCC binary, ternary and quaternary Co alloys (containing respectively Ni, $\mathrm{Ni}$ and $\mathrm{Cr}$, and $\mathrm{Ni}, \mathrm{Cr}$ and $\mathrm{Mo}$ ) and on $\mathrm{Mn}-\mathrm{Cr}-\mathrm{C}$ stainless steels [15]. 
Gold alloys have a behaviour to deformation very similar to that of brass, having a stacking fault energy quite low and with intermediate values between that of $\mathrm{Cu}$ and brass itself. In particular in a gold alloy $(17 \% \mathrm{Ag})$ the presence of very thin twins was detected; they had a very different morphology compared to twins obtained subsequent an annealing treatment after cold working [16].

A very fine twin retrieved in the Mattei gold alloy ring is illustrated in Fig. 11 [3].

If there is the contemporary presence of silver and copper in an 18 carat gold alloy, it is possible to obtain a transformation $\alpha \rightarrow$ AuCuI $+\alpha_{1}$ (being $\alpha_{1}$ a FCC disordered silver rich solid solution) with a characteristic thin plate morphology in which the detection of thin twins may be more difficult.

\section{Summary of the review of the effects of explosions on metals}

The above considerations allow to derive some conclusions about metals undergoing an explosion. Al and its alloys, with low $\sigma_{\mathrm{fs}}$ values and high $\gamma_{\mathrm{sf}}$ values, show slip band formation, even at very high deformation rates. On the contrary, in austenitic stainless steels, which are characterized by low $\gamma_{\mathrm{sf}}$ values, mechanical twinning is induced, eventually accompanied by platelets of $\varepsilon$ martensite. Also $\mathrm{Cu}$ and brass are subject to twinning, more favoured in the latter. The tendency to twinning deformation of $\mathrm{Au}-\mathrm{Ag}$ alloys is intermediate between the ones of $\mathrm{Cu}$ and brass.

The explosions caused by a small charge do not produce considerable deformations in metals and may leave their effect only in a few individual grains or groups of grains distant one from another. In such a situation it is impossible to refer to a stress parameter macroscopically determined, like the yield stress, but it is necessary to consider either $\tau_{\mathrm{c}, \text { slip }}$ or $\tau_{\mathrm{c}, \text { twin, }}$ depending on the deformation mechanism identified by metallographic observations.

\section{CONSIDERATIONS AND CALCULATIONS APPLIED TO THE FORENSIC CASE}

\section{Calculations of critical resolved shear stress for twinning}

7 or $\mathrm{Al}$ and $\mathrm{Al}$ alloys, $\tau_{\mathrm{c}, \mathrm{slip}}$ is to be taken into account because they have high $\gamma_{\mathrm{sf}}$ values and therefore twinning deformation is practically impossible. $\tau_{c, \text { slip }}$ increases due to high deformation rate effects: tests on $\mathrm{Al}$ monocrystals subject to deformations with speeds up to $55 \mathrm{~s}^{-1}$ show an increase of yield stress of more than $100 \%$. Consequently in the case of $\mathrm{Al}$ we must consider a $\tau_{\mathrm{c} \text {,lip }}$ range varying at least between 0.6 and $6 \mathrm{MPa}$. Multiple slip bands detected inside an Al-alloy fragment retrieved during the coroner autopsy of Mr. Mattei’s corpse are visible in Fig. 12.

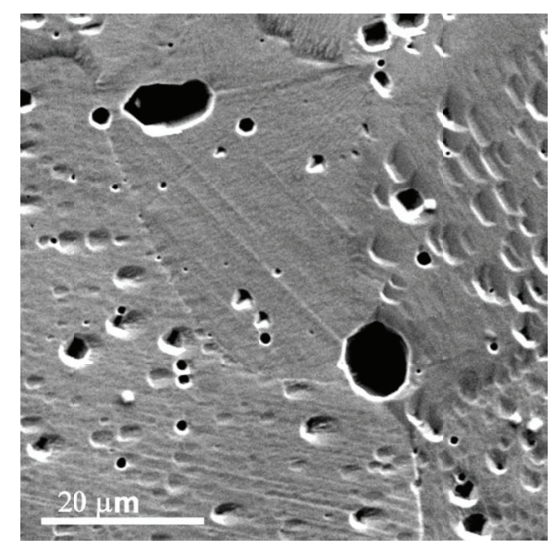

Figure 11: Thin twins formed in the Mattei gold alloy (18 carats) ring, observed by Scanning Electron Microscopy; etching:

$\left(\mathrm{NH}_{4}\right)_{2} \mathrm{~S}_{2} \mathrm{O}_{8}(10 \%)+\mathrm{NaCN}(10 \%)$ solution in water.

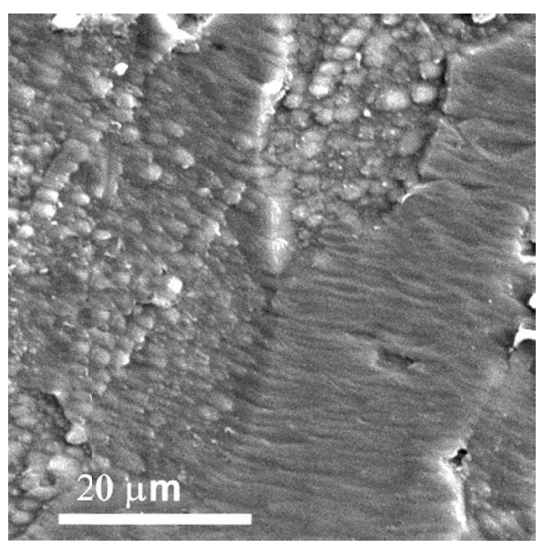

Figure 12: Multiple slip bands formed in an aluminium alloy fragment retrieved during the coroner autopsy of Mr. Mattei's corpse: Keller etchant.

Instead, as it regards austenitic stainless steels, we must refer to $\tau_{\mathrm{c}, \mathrm{twin}}$, even if there might be the contemporary formation of $\varepsilon$ martensite. In the literature no suitable $\tau_{c, \text { twin }}$ values were found for austenitic stainless steels; however it is possible to derive approximate values taking into account some of the $\gamma_{\mathrm{sf}}$ values listed in Tab. 1, as shown below.

An approximate relation between $\tau_{\mathrm{c}, \text { twin }}$ and $\gamma_{\mathrm{sf}}$ is derived from that advanced by Suzuky and Barrett [6], omitting a term becoming infinitesimal when the distance among the dislocations increases:

$$
\tau_{\mathrm{c}, \text { twin }}=\gamma_{\mathrm{sf}} / 2 \mathrm{~b}_{1}
$$


with $b_{1}=a_{0} / \sqrt{ } 6$

where $b_{1}$ is the Burgers vector of the Shockley semi-dislocation and $a_{0}$ is the lattice constant.

Another relation is derived by Remy and Pineau [17], using a formula proposed by Venables [5]:

$$
(1 / \sqrt{ } 3)\left(1 / 3+\mathrm{k} \cdot \tau_{c, \text { twin }} / \mathrm{G}\right) \tau_{\mathrm{ct \text {twin }}} / \mathrm{G}=\gamma_{\mathrm{sf}} / \mathrm{G} \cdot \mathrm{b}
$$

with $\mathrm{b}=\mathrm{a}_{0} \sqrt{2} / 2$

where $b$ is the Burgers vector of a perfect dislocation.

Furthermore, Remy and Pineau [17] compared two curves relating $\tau_{c, \text { twin }} / G$ to $\gamma_{\mathrm{sf}} / \mathrm{G} \cdot \mathrm{b}$ : one with $\tau_{c, \text { twin }}$ derived by the equation (4) and the other one plotting on the ordinate axis $\tau_{c, t w i n}$ experimental data, obtained by several researchers with tests on monocrystals and policrystals. With the second plot other possible values of $\tau_{c, t w i n}$ can be computed.

Finally, a perfect linear correlation can be traced putting on a diagram $\gamma_{\mathrm{sf}}$ in ordinate and the twin- $\tau_{\text {crss }}$ in abscissa and plotting data of every FCC metal for which the pertaining $\gamma_{\mathrm{sf}}$ and $\tau_{\mathrm{c}, \text { twin }}$ values are available in the literature. The derived straight line passes through the origin and its angular coefficient is 0.452 . Then, unknown $\tau_{c, t w i n}$ values can be easily calculated from unknown $\gamma_{\text {sf }}$ data $[3,18]$.

Values of $\tau_{c, t w i n}$, derived for austenitic stainless steel hypothesizing three increasing $\gamma_{\mathrm{sf}}$ values in the $10-20 \mathrm{~mJ} / \mathrm{m}^{2}$ and by the four above mentioned methods, are listed in Tab. 2; G was obtained as 73,660 MPa assuming E=193,000 MPa and v $=0.31$, whereas $\mathrm{a}_{0}$ was taken as $0.359 \mathrm{~nm}$.

If more recent calculations are performed by taking into account both data by Choi e Jin [19], who started from calculations by Inakatsu [20], and incorporating more recent Gonzales et al. results on the effect of $\mathrm{Cu}$ in stainless steels [21] into the equation proposed by Rhodes and Thompson [22], a more precise value of $\gamma_{\mathrm{sf}}$ can be obtained for a stainless steel containing about $3.5 \% \mathrm{Cu}[18]: 31.3 \mathrm{~mJ} / \mathrm{m}^{2}$. Not considering $\mathrm{Cu}$, which was in a small quantity in the stainless steel of the screws of the Triple Indicator (AISI 303) the value falls to only $21 \mathrm{~mJ} / \mathrm{m}^{2}$, which confirms the assumptions reported in Tab. 2.

By making similar calculations basing on Suzuki and Barrett [6], or Remy and Pineau [17], or Firrao et al. [3] works the following Tab. 3 can be further derived [18].

\begin{tabular}{cccccc}
\hline Alloy & $\begin{array}{c}\text { Hypothesized } \\
\gamma_{\mathrm{sf}} \\
\left(\mathrm{mJ} / \mathrm{m}^{2}\right)\end{array}$ & $\begin{array}{c}\text { Suzuky and } \\
\text { Barrett, Eq. 3 }\end{array}$ & $\begin{array}{c}\text { Remy and Pineau, } \\
\text { Eq. 4 }\end{array}$ & $\begin{array}{c}\text { Remy and Pineau } \\
\text { experimental data }\end{array}$ & $\begin{array}{c}\text { Experimental linear } \\
\text { correlation }\end{array}$ \\
Stainless & 20 & 68 & 81 & 103 & 44 \\
Steel & 15 & 51 & 70 & 81 & 33 \\
(AISI 304) & 10 & 34 & 55 & 66 & 22 \\
\hline
\end{tabular}

Table 2: Critical resolved shear stress for twinning $\left(\tau_{c, t w i n}\right)$ for austenitic stainless steels and as a function of staking fault energy $\gamma_{\mathrm{sf}}$ derived by different methods [3].

\begin{tabular}{ccccc}
\hline \multirow{2}{*}{ Metal or alloy } & $\begin{array}{c}\text { Hypothesized } \gamma_{\mathrm{sf}} \\
\left(\mathrm{mJ} / \mathrm{m}^{2}\right)\end{array}$ & $\begin{array}{c}\text { Suzuky and } \\
\text { Barrett }\end{array}$ & $\begin{array}{c}\tau_{\mathrm{c}, \text { twin }}(\mathrm{MPa}) \\
\text { Remy and } \\
\text { Pineau }\end{array}$ & Linear correlation \\
Copper & 80 & 272 & 175 & 177 \\
& 70 & 238 & 163 & 155 \\
& 60 & 204 & 150 & 133 \\
Au-Ag alloy & 45 & 135 & 98 & 100 \\
& 40 & 120 & 92 & 88 \\
Cu containing & 35 & 105 & 86 & 77 \\
austenitic stainless & 20 & 67 & 104 & 44 \\
steel & 25 & 84 & 118 & 55 \\
\hline
\end{tabular}

Table 3: Critical resolved shear stress for twinning $\left(\tau_{c, t w i n}\right)$ for various metals or alloys calculated from $\gamma_{\mathrm{sf}}$ using formulas by various authors. 
Calculation of pressure waves induced by an explosion

The calculated pressure values subsequent an explosion in free air depend both on the target distance and on the mass of the charge used in the experiment. For the purpose of calculating the intensity of pressure waves impinging on an object, the reflected maximum pressures, as recorded by a detector, are more important and always higher than the free air ones. In particular in Tab. 4, the results of an explosion experiment made using an explosive charge corresponding at $364 \mathrm{~g}$ of TNT are reported.

\begin{tabular}{cccc}
\hline $\begin{array}{c}\text { Distance } \\
{[\mathrm{m}]}\end{array}$ & $\begin{array}{c}\text { Calculated pressure in } \\
\text { air }[\mathrm{MPa}]\end{array}$ & $\begin{array}{c}\text { Maximum reflected pressure } \\
{[\mathrm{MPa}]}\end{array}$ & $\begin{array}{c}\text { Multiplying factor } \\
0.42\end{array}$ \\
0.68 & 0.8 & 14.4 & 7.2 \\
\hline
\end{tabular}

Table 4: Free air and reflected pressures at small distances.

\section{Determination of the target-to charge distance}

To relate maximum effective pressure with distance calculations were made, using multiplying factor data, obtained from the above experiment and assuming that a charge equivalent to $150 \mathrm{~g}$ of TN'T was exploded (Tab. 5).

\begin{tabular}{cccc}
\hline $\begin{array}{c}\text { Distance } \\
{[\mathrm{m}]}\end{array}$ & $\begin{array}{c}\mathrm{P}_{\max } \text { in air } \\
{[\mathrm{MPa}]}\end{array}$ & $\begin{array}{c}\text { Effective (x9) } \mathrm{P}_{\max } \\
{[\mathrm{MPa}]}\end{array}$ & $\begin{array}{c}\text { Effective }(\mathrm{x} 7.2) \mathrm{P}_{\max } \\
{[\mathrm{MPa}]}\end{array}$ \\
0.1 & $>16$ & $>144$ & $>115$ \\
0.2 & 6 & 54 & 43.2 \\
0.3 & 2.2 & 19.8 & 15.84 \\
0.4 & 1.25 & 11.25 & 9 \\
0.5 & 0.9 & 8.1 & 6.48 \\
\hline
\end{tabular}

Table 5: Possible effective pressures impinging on an object after an explosion of a $150 \mathrm{~g}$ TNT charge at various distances.

Pressure waves impinging on an object move through the bulk and can be reflected from free surfaces, therefore they can become stronger. For this reason a factor equal to 2 has been used to obtain a plausible maximum pressure inside the material.

Referring to the hypothesis that, in the case of a small charge, slip or twin deformation may be manifested only in isolated grains, thus indicating that the material general yielding has not been reached, maximum shear stress caused by an explosion wave may be evaluated using the following formula which is valid in the elastic range:

$$
\tau_{\max }=(3(1-2 v)) P_{\max } /(2(1+v))
$$

Values of maximum shear stresses in different materials that may be hit from an explosion in an aircraft are also reported in Tab. 6, using the following values for the Poisson modulus: 0.28 and 0.31 for stainless steel, both reported in literature, 0.345 for aluminium and its alloys, 0.44 for gold and its alloys, 0.343 for copper and its alloys.

\begin{tabular}{ccccccc}
\hline Distance & $\begin{array}{c}\text { Effective } \\
\mathrm{P}_{\max }[\mathrm{MPa}]\end{array}$ & $\begin{array}{c}\tau_{\max } \text { in stainless } \\
\text { steel }(v=0.28) \\
{[\mathrm{MPa}]}\end{array}$ & $\begin{array}{c}\tau_{\max } \text { in stainless } \\
\text { steel }(v=0.31) \\
{[\mathrm{MPa}]}\end{array}$ & $\begin{array}{c}\tau_{\max } \text { in } \\
\text { alluminium } \\
{[\mathrm{MPa}]}\end{array}$ & $\begin{array}{c}\tau_{\max } \text { in gold } \\
{[\mathrm{MPa}]}\end{array}$ & $\begin{array}{c}\tau_{\max } \text { in copper } \\
{[\mathrm{MPa}]}\end{array}$ \\
0.1 & $>250$ & $>129$ & $>109$ & $>86$ & $>31$ & $>88$ \\
0.2 & 97.2 & 50.1 & 42.3 & 33.6 & 12.15 & 34.1 \\
0.3 & 35.6 & 18.4 & 15.5 & 12.3 & 4.45 & 12.5 \\
0.4 & 20.2 & 10.42 & 8.8 & 6.98 & 2.52 & 7.1 \\
0.5 & 14.6 & 7.53 & 6.3 & 5.04 & 1.82 & 5.1 \\
\hline
\end{tabular}

Table 6: Maximum shear stresses arising in various metals after impingement of pressure waves originating from a $150 \mathrm{~g}$ TNT charge explosion.

By comparing data from Tab. 2, 3, and 6 it is then possible to derive the approximate distance of an explosive $150 \mathrm{~g}$ TNT charge from an object inside which mechanical twin evidence is discovered. Data in the first two columns of Tab. 6 are in 
complete agreement with the results of recent experiments performed by the authors by exposing to a small charge stainless steel, copper, gold, and aluminium alloys disks [23-25].

\section{APPLICATION OF DEVELOPED THEORIES TO THE STAINLESS STEEL OF THE SCREWS OF THE TRIPLE INDICATOR CASE}

$\mathrm{M}$

etallographic observations of the section of a stainless steel screw allowed to ascertain the presence of mechanical twins in isolated grains at the surface (Figs. 13 and 14) and no twin below the surface (Fig. 15).

The above can be rationalized by inferring that the screw was at the limit of the sphere in which mechanical twins could be still be observed in a stainless steel object. By the same token also the gold ring with scantily observable twins, as illustrated in Fig. 11, was at the limit of its own sphere.
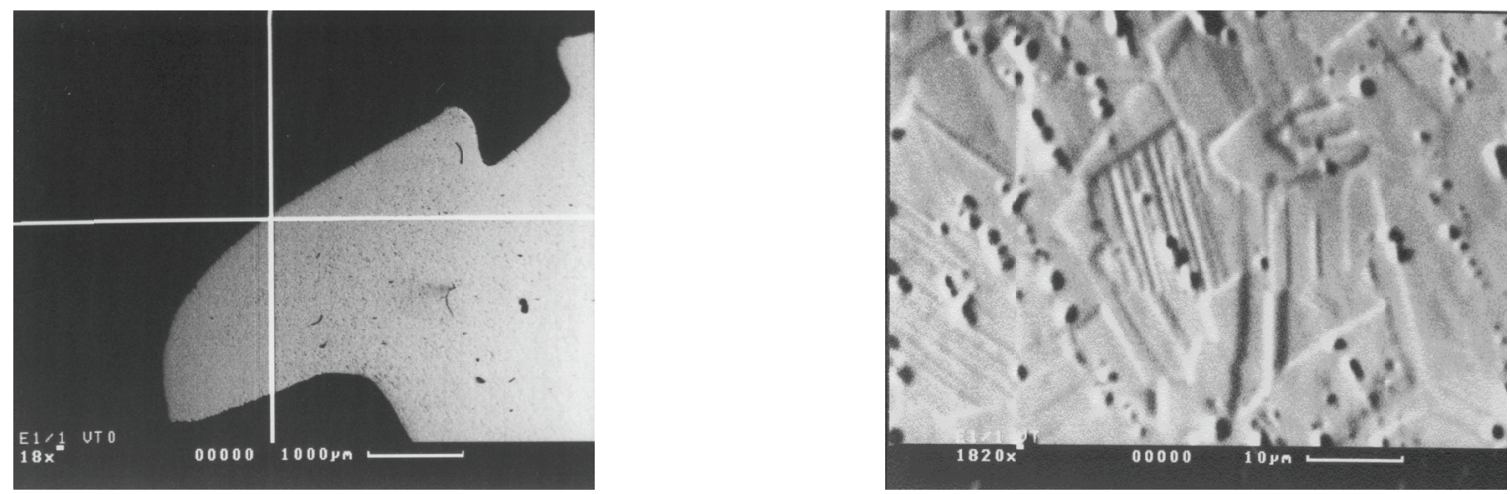

Figure 13: Twins in isolated grains at the surface of a stainless steel screw of the triple indicator.
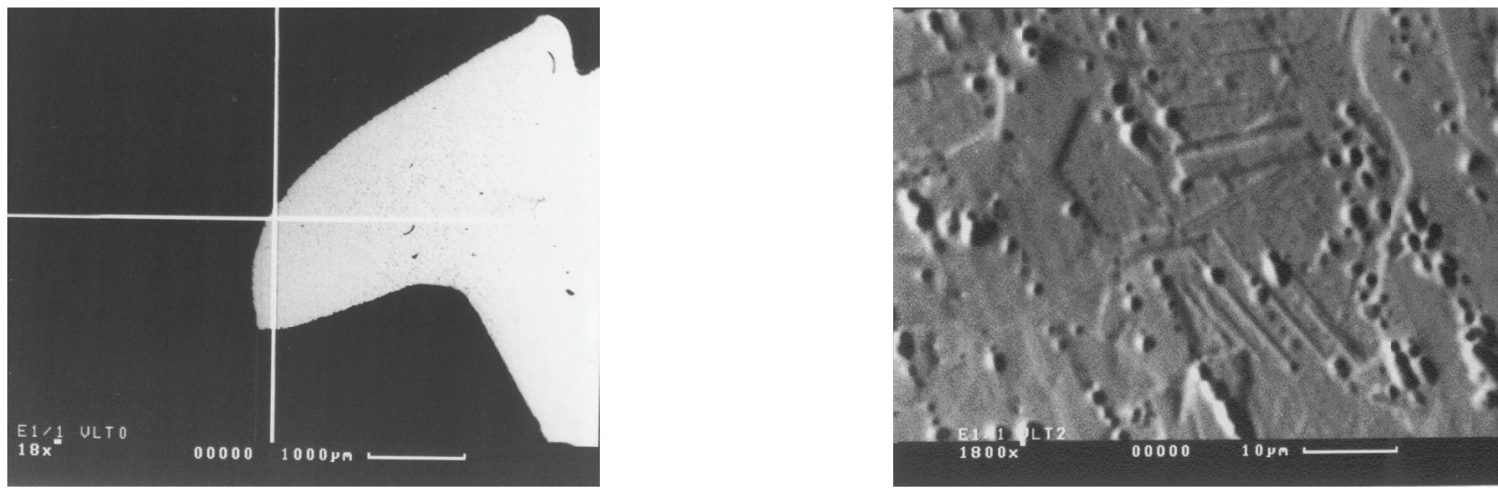

Figure 14: Twins in isolated grains at another point of the surface of a stainless steel screw of the triple indicator.
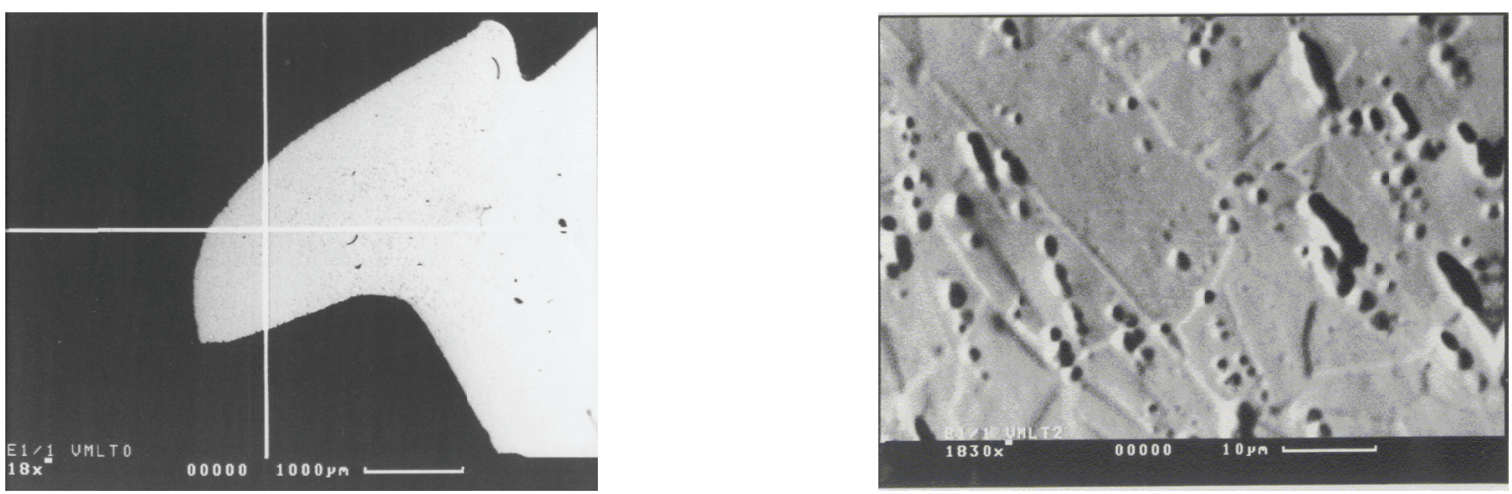

Figure 15: No twins detected below the surface of a stainless steel screw of the triple indicator. 
By considering that the close space of the cockpit cannot be considered similar to a free space, and that waves increase their pressures by multiple reflections, distances coming from the combined considerations of Tab. 2, 3, and 6 have to be at least doubled. From the above calculations and considerations it was then possible to conclude that with a $150 \mathrm{~g}$ TNT charge the distance charge-to-screw could be 40-45 cm and the distance charge-to-ring could be $20-25 \mathrm{~cm}$.

\section{WHERE WAS THE BOMB PLANTED?}

s it was said before the locations of the screws and of the gold ring where fairly well positioned, as illustrated in
Fig. 16.
Then the two spheres centered on the tips of the arrows had a circumference as an intersection. Such a line lied in the air most of its perimeter but a small portion behind the dashboard.

In that position the bomb had been planted from the exterior of the cockpit (Fig. 17).

After the calculations the coroner remembered that he had found a small yellow piece embedded in Mattei's hand, clearly coming from the yellow-red leverage in the middle of the lowest part of the dashboard. Such a revelation confirmed both the position of Mattei's hand and that the bomb had been planted behind the dashboard. The skin-stripped hand, retrieved high on a tree branch in the morning of October 28, 1962, had given its final contribution to confirm the solution of the case.

A final visit to the twin plane stationing in a Nice Airport hangar and belonging at the time of the forensic investigation to an Italian industrialist, confirmed that, by entering from a small manhole on the right of the forward fuselage, an adequate position could easily be reached by hand to plant a small explosive charge behind the dashboard in the center of the back of it.

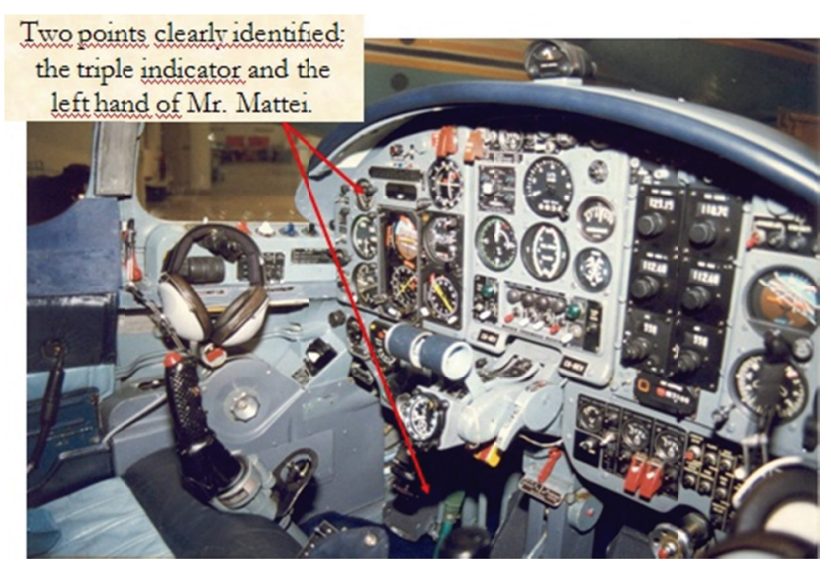

Figure 16: Reconstruction of the cockpit scene at the moment of the charge explosion.

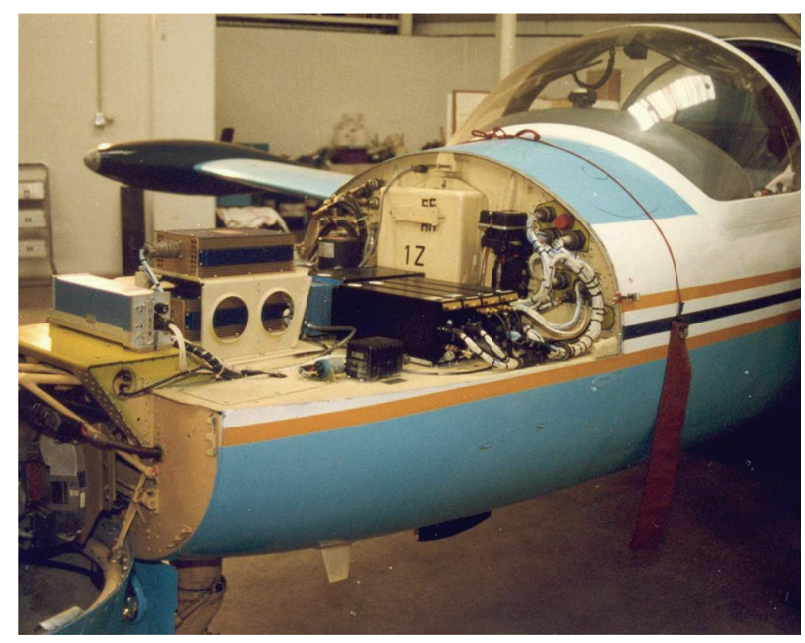

Figure 17: Forward portion of the fuselage. 


\section{CONCLUSION}

$\mathrm{T}$ he Mattei affair had been solved: a small charge bomb had been planted behind the dashboard from the exterior of the plane.

\section{LIST OF REFERENCES}

[1] G. E. Dieter, Mechanical Metallurgy, McGraw-Hill Kogakusha, New York, N.Y., USA, (1976) 51.

[2] C. S. Smith, Trans. M.S. AIME, 214 (1958) 574.

[3] D. Firrao, G. Ubertalli, and E. Cordano, Technology, Law and Insurance, 4 (1999) 23.

[4] E. Schmidt, G. Siebel, Z. Elektrochem., 37 (1931) 447.

[5] J. A. Venables, in Deformation Twinning, R.E. Reed, J.P. Hirth, H.C. Rogers eds., Gordon \& Breach, New York, N.Y., (1964) 77.

[6] H. Suzuki, C. Barrett, Acta Metall., 6 (1958) 156.

[7] L. Remy, A. Pineau, B. Thomas, Mat. Sc. Engnr., 36 (1978) 47.

[8] R. M. Latanision, A.W. Ruff, Metall. Trans., 2 (1971) 505.

[9] F. Lecroisey, B. Thomas, Phys. Status Solidi A, 2 (1970) K217.

[10] F. Lecroisey, A. Pineau, Metall. Trans., 3 (1972) 387.

[11] N. J. Petch, J. Iron Steel Inst., 174 (1953) 25.

[12] E. O. Hall, , Proc. Phys. Soc., B64 (1951) 747.

[13] M. A. Meyers, U.R. Andrade, A.H. Chokshi, Metall. Mater. Trans. A, 26 (1995) 2881.

[14] H. J. Kestenbach, M.A. Meyers, Metall. Trans. A, 7A (1976) 1943.

[15] L. Remy, A. Pineau, Metall. Trans. A, 5A (1974) 1963.

[16] S. Appleton, G.E. Dieter, M.B. Bevers, Trans. M.S. AIME, 221 (1961) 90.

[17] L. Remy, A. Pineau, Mat. Sc. Engnr., 26 (1976) 123.

[18] D. Firrao, P. Matteis, C. Pozzi, Acc. Sc. Torino - Mem. Sc. Fis. Ser. V, 29 (2005) 3.

[19]J. Y. Choi, W. Jin, Scripta Materialia, 36 (1996) 99.

[20] N. Inakatsu, H. Yamamoto, M. Ishio, J. Japan Inst. Metals, 48 (1984) 71.

[21] M. Gonzalez, C.S.B. Castro, V.T.L. Buono, J.M.C. Vilela, M.S. Andrade, J.M.D. Moraes, M.J. Mantel, Mater. Sci. Eng. A, $343(2003) 51$.

[22] G. Rhodes, A.W. Thompson, Metall. Trans. A, 8A (1977) 1901.

[23] Firrao, P. Matteis, G. Scavino, G. Ubertalli, C. Pozzi, M.G. Ienco, P. Piccardo, M.R. Pinasco, E. Stagno, G. Costanza, R. Montanari, M.E. Tata, G. Brandimarte, S. Petralia, Metall. and Mater. Trans. A, 38 (2007) 2869.

[24] D. Firrao, P. Matteis, C. Pozzi, M.G. Ienco, G. Pellati, M.R. Pinasco, R. Montanari, M.E. Tata, CALPHAD, 33 (2009)76.

[25] D. Firrao, P. Matteis, C. Pozzi, Materials Science Forum, 638-642 (2010) 1029. 